\title{
Em defesa de uma atitude poética para a interpretação nas práticas de letramentos em contexto escolar
}

\author{
In defense of a poetic attitude towards \\ interpretation during literacy practices in \\ school context
}

Cinara Monteiro Cortez*

Pontifícia Universidade Católica do Rio de Janeiro (PUC-Rio)

Rio de Janeiro - Rio de Janeiro/Brasil

RESUMO: O presente texto busca discutir a questão da interpretação, especialmente durante as práticas de letramentos em contexto escolar, reagindo a concepçōes teóricas que norteiam as reflexôes aqui apresentadas e que posicionam a linguagem como um instrumento de representação do mundo ou como um fazer, e também àquelas que se encontram na tensão entre esses polos. Nesse sentido, a proposta deste texto é defender uma atitude mais poética para o trabalho da interpretação nas práticas de letramentos em contexto escolar, em uma postura de reação ao texto, que envolve a noção de ato de leitura como performance, e não como um exercício de decodificação ou descoberta.

PALAVRAS-CHAVE: letramentos, interpretação, atos de leitura, representação, práxis.

ABSTRACT: The present text seeks to discuss the matter of interpretation, especially during literacy practices in school context, reacting to theoretical conceptions which indicate the reflections presented here and which position language as an instrument to represent the world or as praxis, and also those ones which are positioned in the tension between those poles. Therefore, the objective of this work is to defend a more poetic attitude towards the work of interpretation during literacy practices in school context, adopting a posture of reaction to the text, which involves the notion of reading acts as performances, and not as a decoding or a discovery exercise.

KEYWORDS: literacy, interpretation, acts of reading, representation, praxis.

\footnotetext{
* cinaracortez@hotmail.com. Doutoranda em Estudos da Linguagem pela PUCRio, sob orientação da Profa. Dra. Maria das Graças Dias Pereira.
} 
Você conhece os meus cadernos, não conhece? Quando eu saio montado num cavalo, por minha Minas Gerais, vou tomando nota de coisas. O caderno fica impregnado de sangue de boi, suor de cavalo, folha machucada. Cada pássaro que voa, cada espécie, tem voo diferente. Quero descobrir o que caracteriza o voo de cada pássaro, em cada momento. Não há nada igual neste mundo. Não quero palavra, mas coisa, movimento, voo.

Guimarães Rosa, em entrevista a Pedro Bloch

A questão contemporânea da interpretação emerge como reação ao paradigma representacional da linguagem ao pensá-la como práxis, um fazer, como em Guimarães Rosa, na epígrafe deste texto: uma linguagem sem adjacências, um escrever-fazer (ou ler-fazer) em que não há um fora, um além. Uma linguagem que não diz, pois ela já é; é sangue, suor e machucado na materialidade abstrata do caderno de notas, onde a palavra tem de ser tudo que não apenas palavra, pois que é coisa, movimento, voo. Linguagem que se vive, linguagem como vida.

Entretanto, essa aspiração em experienciar a linguagem que cria a própria experiência arrasta consigo toda a força cultural e histórica da representação, da linguagem que quer dizer algo; um algo que preexiste e para o qual ela aponta; em que interpretar pode significar refazer o caminho do autor, ou decodificar, desvelar; escrever/ler (ou pintar, esculpir, compor...) para traduzir um pensamento, uma ideia, algo que está por trás (ou dentro) da obra.

Considerar cada um desses lados, ou mesmo a tensão entre eles, é especialmente importante para os interessados em linguagem. Nesse caso, o professor, particularmente o professor de línguas, está inserido no cerne dessas discussões, já que a linguagem parece ser tanto instrumento quanto objeto de seu trabalho: é problema, ferramenta e solução; origem, meio e fim. Como, então, pensar a questão mais específica da interpretação para as práticas pedagógicas, em especial remetendo à discussão sobre os letramentos, isto é, sobre os usos sociais que se utilizam da leitura e da escrita (dentre os quais, os letramentos escolares)?

Buscando uma forma de dialogar com as discussões que serão fomentadas em torno de um mesmo foco, a proposta deste texto é defender uma postura mais poética para o trabalho da interpretação nas práticas de letramentos no contexto escolar, reagindo a concepções teóricas que norteiam as reflexões acerca da questão da interpretação e dos letramentos. 


\section{Decifra-me ou devoro-te}

Quando pensamos a questão da interpretação nas práticas escolares de letramentos, é possível observar uma maior inclinação para caminhos que indicam uma relação mais objetiva com o texto ${ }^{1}$ (ou qualquer obra, de forma mais generalizada), uma relação que separa o sujeito-leitor do texto-objeto (ou obra-objeto), no intuito de buscar o que as palavras (ou imagens, sons, etc.) "querem dizer", e/ou de revelar a intenção do autor por trás dessas palavras. $\mathrm{O}$ texto/obra, como objeto, parece conter uma série de informações codificadas possíveis de ser descobertas, ou traduzidas, mediante o exercício de processos de análise que levam à interpretação e, finalmente, à sua compreensão, mas que é somente acessível para aqueles que souberem como fazer. Assim, o papel do professor, no que diz respeito ao assunto, configura-se em ensinar como fazêlo - as formas, maneiras e técnicas para descobrir o que as palavras, imagens, cores, sons, etc. encobrem. E o papel do aluno é aquele de interpretar, de saber o que o texto/obra realmente é, o que significa, o que esconde atrás de si, muitas vezes buscando a experiência-origem do autor, outras, traduzindo-o, revelando que isto quer, na verdade, dizer aquilo.

Essa noção está diretamente relacionada com o posicionamento de I. A. Richards sobre o papel do crítico, de acordo com De Man:

Para Richards, o problema da crítica consiste em apreender correctamente o valor significativo ou o significado da obra, correspondência exacta entre a experiência de que o autor partiu e a sua expressão comunicada: para o autor, o trabalho de elaboração formal consiste em construir uma estrutura linguística que corresponda, de modo tão justo quanto possível, a uma experiência inicial. Supondo que tal correspondência seja estabelecida pelo autor, poderá então existir para o leitor; aquilo a que se chama comunicação é seu correlato (DE MAN, 1999, p. 253).

Nesse sentido, para Richards, a experiência torna-se uma elaboração formal - o trabalho do autor, e, através do refazer o caminho do autor de volta a sua experiência, atinge-se o conhecimento. Isso é possível porque, para Richards, as palavras (que também são símbolos, como os gestos, imagens,

\footnotetext{
${ }^{1}$ Em quase todo o trabalho, texto equivalerá a qualquer obra de arte em se tratando da questão da interpretação, já que muitos autores citados tratam mais especificamente da crítica literária. Apenas em momentos oportunos, de acordo com o que os autores argumentam, haverá algum tipo de distinção entre os tipos de obras.
} 
etc.) só representam ou significam algo quando um pensador as usa, e são instrumentos que medeiam a relação entre o que se pensa e o que se quer dizer, e entre falante (podemos também considerar o autor) e ouvinte (leitor/ espectador):

Entre um pensamento e um símbolo são mantidas relações causais. Quando falamos, o simbolismo que empregamos é causado, em parte, pela referência que estamos fazendo e, em parte, pelos fatores sociais e psicológicos [...] Quando ouvimos o que foi dito, os símbolos fazem com que desempenhemos um ato de referência e, ao mesmo tempo, com que assumamos uma atitude que, de acordo com as circunstâncias, será mais ou menos semelhante ao ato e a atitude de quem falou. [..] Entre Pensamento e Referente há também uma relação; mais ou menos direta [...] ou indireta [...]. Entre símbolo e referente não existe qualquer relação pertinente a não ser uma indireta, que consiste em seu uso por alguém para representar o referente (OGDEN; RICHARDS, 1976, p. 32-33).

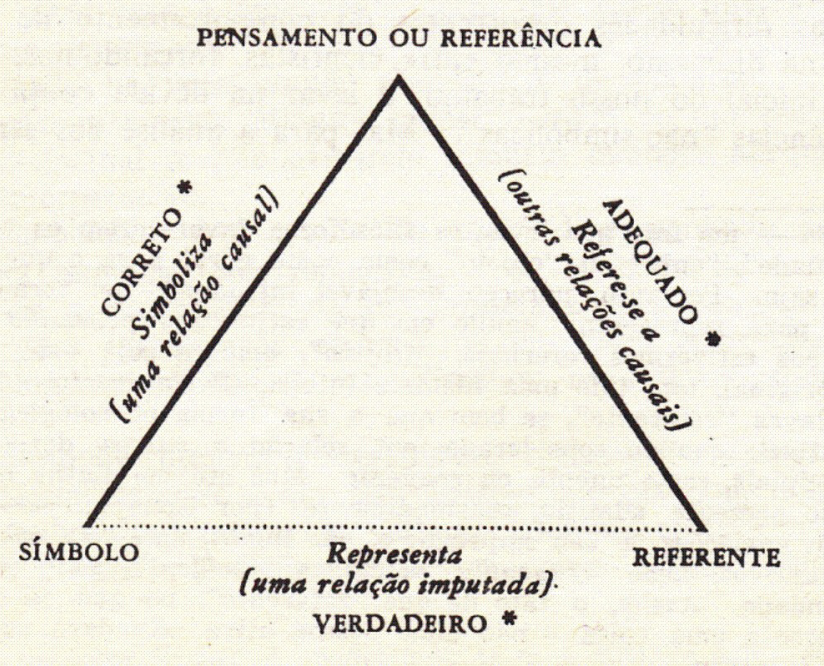

FIGURA 1 - Relação entre símbolo, pensamento/referência e referente Fonte: OGDEN; RICHARDS, 1976, p. 32.

Observando o diagrama, explicam os autores, "um símbolo verdadeiro = um símbolo que registra corretamente uma referência adequada” (OGDEN; RICHARDS, 1976, p. 117). Assim, de acordo com nossa discussão, pensamento e referente podem apresentar equivalência à experiência (do autor) 
e à obra, respectivamente, em que o texto em si, as palavras (ou imagens, ou sons, ou gestos...), são os símbolos que devem registrar adequadamente essa experiência.

Embora a complexidade da proposta de Ogden e Richards não possa ser explorada aqui, torna-se difícil não associar a noção de pensamento/referência, ou "uma teoria que relacione palavras com coisas através das ideias, se estas existirem, que elas simbolizam" (OGDEN; RICHARDS, 1976, p. 29), com o que Aristóteles já apresentava em De interpretatione.

Para Aristóteles, as palavras são símbolos dos estados da alma (vox). Elas ligam-se aos conceitos (as afecções da alma - conceptus), que, por sua vez, estão relacionados com as coisas ( rex) (no entanto, coisas e palavras não possuem relação de semelhança). Na visão aristotélica, a linguagem é também uma forma de representação do pensamento, é o "espelho da mente". Ogden e Richards (1976), contudo, apresentam uma crítica a Aristóteles, especialmente sobre a ênfase em sua Lógica, em detrimento dos "vários ramos da fala significante [que] são deliberadamente excluídos", e acrescentam que "ele [Aristóteles] insiste aí em que as palavras são, primordialmente, sinais de afecções mentais e só secundariamente são das coisas de que constituem semelhanças" (OGDEN; RICHARDS, 1976, p. 56).

Para além do texto e em relação à obra de arte em geral, Susan Sontag $(1965)^{2}$ reage à noção que permeia a visão representativa da linguagem, salientando a insistente prevalência do conteúdo (ou a ideia de uma essência) que parece incorporar o projeto da interpretação. Para a autora, mesmo abandonando a concepção de representação - da arte como expressão de algo exterior -, a noção de que a arte "quer dizer" alguma coisa ainda persiste (mesmo que por hábito), como se a interpretação fosse sempre e apenas uma tarefa de tradução.

Isso remete à noção do conduto, da linguagem (ou obra) que pode "transferir pensamentos e sentimentos humanos", em que palavras (e obras) possuem interiores - onde os significados residem - e exteriores (REDDY, 2000 , p. 8-9). Ademais, interpretar, em um posicionamento mais representativista, é também controlar o ato da leitura. Um controle necessário não apenas para conter um sem número de interpretações, mas para garantir um significado "verdadeiro", pois, como argumenta Locke:

${ }^{2}<$ http://pt.scribd.com/doc/17146409/Contra-a-Interpretacao-Susan-Sontag>. 
Como as palavras são destinadas a serem sinais de minhas ideias para tornar estas ideias conhecidas dos outros, não por uma significação natural, mas por uma imposição voluntária, é manifesta a fraude, e há abuso quando se faz significar as palavras, umas vezes uma coisa, outras vezes outra; procedimento propositado que não pode ser atribuído senão a uma grande insensatez ou a uma extrema desonestidade (LOCKE, 2005, p. 672).

Logo, toda interpretação apoiada na representação assinala a insistência no método, nas normas, nos limites, como forma de criar uma estabilidade para a tarefa. Uma contenção do desvario: desde Aristóteles, ao propor sua Poética e sua Retórica, em que normas são criadas para lidar com o desvio, até, por exemplo, a Semiótica de Umberto Eco (1993), que permite ao leitor (co)construir o texto que lê, desde que o texto seja tratado como um "todo coerente" para evitar a "interpretação paranóica” (remetendo a Santo Agostinho, para o qual qualquer interpretação deve ser regulada pelo próprio texto, onde diferentes partes devem confirmar o que é interpretado).

Controlar/restringir a interpretação é também pacificar, apaziguar tensões, ou, como De Man coloca em relação a Richards, uma "crítica [que] é tranquilizadora [...] Ao reconduzir a linguagem poética ao plano da linguagem-comunicação e ao recusar-se a acreditar numa experiência estética distinta das outras experiências humanas" (DE MAN, 1999, p. 257).

Nesse sentido, a noção de um conteúdo, uma intenção do autor por trás do texto, algo a ser descoberto, traduzido, desvelado, através de normatização e contenção, pode colaborar com a ideia de controle do desvario de interpretações entre os alunos e de pacificação de tensões, paradoxos e ambiguidades que os textos (e obras em geral) podem fazer emergir durante as práticas de letramentos escolares.

Assim, resta aos alunos decifrar o texto e/ou o que devem interpretar...

\section{Não há ribalta}

Se o caminho da normatização, do controle ou dos limites parece apaziguar as tensões e, portanto, regulamentar os processos do labor interpretativo (também aquele do trabalho do professor e da tarefa dos alunos), seu oposto parece desafiar a possibilidade de se investir na prática pedagógica (ao menos dentro do que consideramos em nosso sistema escolar) por sua ausência de fronteiras e por possibilidades ilimitadas. 
Isso se dá pelo fato de que a linguagem como práxis não pressupõe um sistema como âncora, em que as regras preexistem e podem ser aprendidas (e, portanto, ensinadas) para ser executadas durante seu uso. A linguagem, tomada dessa forma, requer adesão: só se pode conhecer as regras jogando; nunca de antemão, pois a linguagem não existe em um lugar específico e, portanto, não pode ser contingente a nada (WITTGENSTEIN, 1999). Nesse sentido, não há fronteiras entre pensamento e linguagem. A linguagem não se reduz a uma teoria geral, não possui vocação, pois que é, tão somente, um conjunto de práticas: linguagem como forma de vida.

Considerar a linguagem dessa forma incorre também em perceber o próprio texto (obra) como práxis e, como nos diz Barthes (2002, p. 23), perceber que "na cena do texto não há ribalta", pois não existe uma relação sujeito-objeto, ou uma relação entre um escritor-ativo e seu leitor-passivo.

Isso aponta para a impossibilidade de se falar de algo dentro da própria coisa, uma metalinguagem sobre a própria linguagem que desafia o empreendimento da interpretação, pois, como argumenta Barthes (2002) sobre o escritor e leitor (de fruição):

Com o escritor de fruição (e seu leitor) começa o texto insustentável, o texto impossível. Este texto está fora-de-prazer, fora-da-crítica, a não ser que seja atingido por um outro texto de fruição: não se pode falar "sobre" um texto assim, só se pode falar "em" ele, à sua maneira, só se pode entrar num plágio desvairado, afirmar histericamente o vazio da fruição (e não mais repetir obsessivamente a letra do prazer) ${ }^{4}$ (BARTHES, 2002, p. 29).

A proposta barthesiana parece se aproximar da ideia de um viver-o-texto sobre o qual não se pode dizer, já que estamos nele. Nesse sentido, o projeto de uma interpretação que revele o que existe por trás (ou dentro das palavras/

\footnotetext{
${ }^{3}$ Embora a crítica de De Man (1999) nos mostre um Barthes preocupado com a forma (e também o conteúdo), em $O$ prazer do texto (2002), temos um texto barthesiano mais sensível à escrita e à leitura como práxis (em Barthes, fruição).

${ }^{4}$ Barthes distingue fruição e prazer. Para ele, a fruição é "in-dizível" e "inter-dita", ao passo que o prazer é dizível, pois "o escritor de prazer (e seu leitor) aceita a letra; renunciando à fruição, tem o direito e o poder de dizê-la: a letra é seu prazer [...] a crítica versa sempre sobre textos de prazer; jamais sobre textos de fruição" (BARTHES, 2002, p. 28). O texto de fruição seria, assim, o que se aproximaria do escrever/fazer e ler/fazer.
} 
obras) está fadado ao fracasso, sendo, portanto, impossível de se estabelecer pela própria forma como se encara o texto.

Também encontramos essa mesma noção de impossibilidade de se interpretar o texto (não apenas o de fruição no sentido barthesiano) em muitos autores, que se afastam de uma concepção de essência do texto, alcançável através de uma metodologia rigorosa, pois tal noção "é tão errada quanto a ideia aristotélica de que há algo que uma substância realmente é, intrinsecamente, em contraposição ao que ele é apenas aparentemente, acidentalmente ou relacionalmente" (RORTY, 1993, p. 121).

Esse tipo de visão abre um mundo de possibilidades que permite reagir ao texto/obra, $\mathrm{m}$ vez de tentar descobrir ou traduzir o que ele (ou seu autor) quer dizer. Como nos convoca a proposta pragmatista, a única coisa possível de se fazer com um texto é usá-lo e realizar, assim, uma leitura "inspirada", de forma que este possa transformar a vida (RORTY, 1993, p. 125). Ou, como propõe Culler (1993), levar a interpretação ao extremo, limitada por um contexto que é sempre ilimitado, e como há sempre novos contextos, não é possível estabelecer limites.

No entanto, há nessas propostas que sinalizam ao desvario certo apaziguamento, um retorno à tranquilidade que o rigor do método também proporciona, porque se tudo é possível, a tensão, a ambiguidade, o paradoxo aí também não existem.

\section{As mesmas (antigas) questões ou novas questões?}

As discussōes em torno da interpretação vão também ao encontro das teorias sobre os letramentos, especialmente ao se pensar sobre as práticas pedagógicas de letramentos no contexto escolar. $\mathrm{O}$ assunto requer pensar em como tratar os gêneros que estão relacionados aos letramentos em se considerando as questôes abordadas sobre a interpretação. Nesse sentido, posicionar-se sobre a questão da linguagem orientará a(s) maneira(s) como os letramentos serão encarados.

Circunscritos na linguagem, onde construímos nossos significados a partir de nossas relações socioculturais e históricas, os letramentos são considerados práticas sociais que se utilizam da leitura e da escrita (aqui, leitura e escrita para além do texto escrito) (BARTON; HAMILTON, 1998; GREEN et al., 1994; COPE; KALANTZIS, 2000; KLEIMAN, 1995; ROJO, 2009; SOARES, 1998, 2004; SOUZA, 2011; STREET, 1984, 1993). 
Rojo (2009) ressalta o caráter plural do termo (letramentos), pois considera que há diferentes tipos: aqueles dominantes, associados a "organizaçôes formais tais como a escola, as igrejas, o local de trabalho, o sistema legal, o comércio, as burocracias" (ROJO, 2009, p. 102), e, portanto, valorizados e legitimados; e os letramentos locais ou vernaculares, cuja origem remete à vida cotidiana e às culturas locais (como, por exemplo, apostar no jogo de bicho, grafitar, compor um rap ou usar as redes sociais na internet). Nessa concepção, a escola deve possibilitar a participação ampla de seus alunos nas práticas de letramentos na vida em sociedade, de forma crítica, democrática e ética. Assim, para que isso seja possível, a educação linguística deve considerar: (a) os multiletramentos (letramentos múltiplos), reconhecendo e valorizando os letramentos vernaculares e das culturas locais, integrados aos letramentos valorizados, canônicos, universais e institucionais; (b) os letramentos multissemióticos, que incorporam as novas mídias e multimodalidades, assim como outras semioses além da escrita (as cores, os sons, o design, etc.), presentes na vida contemporânea e distantes do contexto escolar em muitos sentidos; e (c) os letramentos críticos e protagonistas, que, segundo a autora, são "requeridos para o trato ético dos discursos em uma sociedade saturada de textos e que não pode lidar com eles de maneira instantânea, amorfa e alienada" (ROJO, 2009, p. 108).

De acordo com essa noção, os letramentos são práticas, são as formas como fazemos uso da escrita e da leitura (para além do texto escrito) em nossas vidas; dentre eles, estão os letramentos escolares, aqueles que pertencem ao ambiente da escola, como escrever uma redação, pesquisar para um trabalho, debater sobre um tema em particular, apresentar um seminário, ler um texto literário para responder a perguntas, dentre muitos outros.

O papel dos letramentos escolares (especialmente em relação à linguagem), de acordo com os Parâmetros Curriculares Nacionais do Ensino Médio, é o de "instrumentalizar o aluno para seu desempenho social. Armálo para poder competir em situação de igualdade com aqueles que julgam ter o domínio social da língua" (BRASIL, 2000, p. 22). Logo, o papel do professor é "letrar" o aluno de acordo com o que este precise para fazer parte da sociedade e para provar, quando necessário, que possui determinado conhecimento que alguns acreditam dominar mais que outros. Assim, podemos considerar que os letramentos escolares passam, de uma forma ou de outra, pela questão da interpretação, pois o objetivo a ser atingindo é a compreensão de algo para se chegar a certo conhecimento. 
Mas como ensinar a interpretar? Controlando, limitando através de métodos, técnicas e critérios, para alcançar certa adequação necessária entre o texto/obra e seu leitor? Ou incentivando a interpretação sem fronteiras, sem amarras? Ademais, se pensarmos os letramentos como uso, prática, a própria noção de ensino parece falhar, pois como ensinar a interpretar, senão já interpretando? É realmente necessário interpretar como forma de compreender algo? Existe alguma forma de "possibilitar a participação ampla" dos alunos nos letramentos da vida em sociedade no espaço escolar, como sugere Rojo (2009), sem "ensinar" aos alunos como fazê-lo? Podem os alunos ser letrados nessas práticas escolares apenas tomando parte delas e reconhecendo-lhes as regras durante seu uso?

Entre as indagações e considerações geradas a partir da discussão sobre linguagem, interpretação e letramentos, destaco, também, a imensa responsabilidade do professor em posicionar-se e agir, com o absurdo peso em seus ombros de fazer a escolha adequada, aquela que conduzirá sua prática aos resultados esperados (pela escola, pelos pais, pelo sistema, pelo governo, e, talvez, pelos alunos). Entretanto, outras enormes responsabilidades estão em jogo, pois interpretar é, também, ir além das expectativas escolares e dos números governamentais. Como aponta Sontag, a interpretação é parte de nossa história e cultura, não um valor absoluto. Nesse sentido, ela pode ser um ato libertador, que nos ajuda a rever e transpor valores; mas ela também pode ser "reacionária, impertinente, covarde, asfixiante", de acordo com o contexto (SONTAG, 1965, p. 4). ${ }^{5}$

É claro que, entre as opções que Sontag nos mostra, escolheríamos sempre a interpretação como liberação. Mas, das opçōes, o que é possível na prática pedagógica? E como responder a todas essas perguntas que a discussão faz emergir e que nos impulsionam, de alguma forma, a optar por um determinado posicionamento sobre a linguagem? Será realmente uma questão de escolha de lados?

Esclareço, contudo, que não proponho respostas ou algum tipo de método para orientar a prática pedagógica acerca das questôes levantadas aqui. Tampouco creio haver respostas certas ou verdades absolutas para essas perguntas. No entanto, acredito que as consideraçóes e reflexões possam ajudar a criar inteligibilidade sobre as diferentes discussōes em torno do assunto, sem reduzi-las a certezas ou afirmações exaustivas e/ou conclusivas.

${ }^{5}<$ http://pt.scribd.com/doc/17146409/Contra-a-Interpretacao-Susan-Sontag>. 
Entretanto, considero o assunto uma das urgências nas discussões correntes sobre o panorama da educação no Brasil. Isso porque uma das causas dos problemas de nosso sistema educacional, especialmente em relaçáo ao baixo índice dos alunos nos testes governamentais que servem para medir o conhecimento acadêmico aprendido, seria a dificuldade da escola (principalmente a pública) em ensinar "corretamente" seus alunos a ler e escrever. Inúmeras pesquisas do governo e notícias que circulam nas diferentes mídias insistem no alto número do que chamam "analfabetos funcionais", isto é, aquelas pessoas que, mesmo tendo sido inseridas no sistema escolar (muitas com formação completa), não conseguem ler e compreender um texto "adequadamente".

Nesse sentido, esse tipo de pensamento corrobora a noção de linguagem como representação objetiva de um sistema, um código, um repertório de itens regidos por regras, cuja verdade possui uma coerência interna e é sua essência. Logo, o erro é o mau uso desse sistema, e, portanto, não há lugar para o desvio ou o desvario de interpretaçôes; ao passo que observar a linguagem como práxis desloca essa noção, e o erro e o desvio tornam-se apenas um fazer diferente dentro do jogo da linguagem.

\section{Um canto de dor (que é a dor e outra coisa)}

Embora as questóes se ampliem e o debate tome diversos rumos, a discussão parece ainda pairar sobre como encarar a linguagem: uma forma de representar o mundo ou uma forma de viver o próprio mundo.

Retomando as questóes do interpretar, recordo um trecho em que Guimarães Rosa, em entrevista a Günter Lorenz, fala sobre seu processo de escrever-viver o sertão:

[...] nós, os homens do sertão, somos fabulistas por natureza. Está no nosso sangue narrar estórias; já no berço recebemos esse dom para toda a vida. Desde pequenos, estamos constantemente escutando as narrativas multicoloridas dos velhos, os contos e lendas, e também nos criamos em um mundo que às vezes pode se assemelhar a uma lenda cruel. Deste modo a gente se habitua, e narra estórias que correm por nossas veias e penetram em nosso corpo, em nossa alma, porque o sertão é a alma de seus homens [...] A única diferença é simplesmente que eu, em vez de contá-las, escrevia. [...] Instintivamente, fiz então o que era justo, o mesmo que mais tarde eu faria deliberada e conscientemente [...]. Quem cresce em um mundo que é literatura pura, bela, verdadeira, real deve algum dia começar a escrever, se tiver 
uma centelha de talento para as letras. É uma lei natural, e não é necessário que atrás disto haja ambições literárias (ROSA, 1965). ${ }^{6}$

Vemos em Guimarães Rosa o movimento de uma escrita que vive, em vez de apenas descrever, representar, comunicar ou significar. E não só durante sua escrita ou narração, mas também na recepção das histórias vivas dos outros, em um ato de escutar que é também ler-criar aquele mundo. Ele opta por viver no texto (escrito ou contado) as histórias de sua própria vida, de seu mundo, pois que mundo e literatura lhes são a mesma coisa. No entanto, o ato de escrever, em Guimarães Rosa, ao mesmo tempo em que é algo que acontece, uma "lei natural", instintiva, é também uma performance, consciente de sua elaboração diferenciada de um viver somente.

De outro modo, Sartre nos diz que "um grito de dor é sinal da dor que o provoca. Mas um canto de dor é ao mesmo tempo a própria dor e uma coisa que não a dor. [...] é uma dor que não existe mais, é uma dor que é" (SARTRE, 2004, p. 11-12, grifo do autor). Para o autor, a literatura é um tipo de arte diferenciada das outras, pois, ao passo que o escritor (prosador) trata dos significados, o pintor ou o escultor, por exemplo, cria coisas. No entanto, ele também distingue a prosa da poesia, a qual ele aproxima das outras artes: o escritor de prosa é aquele que lida com signos e que se utiliza das palavras para significar; o poeta se recusa a utilizar a linguagem, pois considera as palavras como coisas, "está fora da linguagem, vê as palavras pelo avesso, como se não pertencesse à condição humana” (SARTRE, 2004, p. 14). O poeta, como o pintor ou o escultor, também cria coisas.

Sartre (2004) transita nessa tensão entre a linguagem que quer dizer, representar algo, e aquela que cria. Ele compreende que o falante está na linguagem, é investido pelas palavras, mas, ao mesmo tempo, a linguagem é um outro lugar do qual é possível colocar-se de fora. Podemos perceber a linguagem quando outra pessoa faz uso dela, mas a sentimos ao mesmo tempo que a ultrapassamos quando a usamos. Entretanto, segundo o autor, usar a linguagem ou observar alguém fazer uso dela significa fazer parte de uma atividade em curso.

É nesse paradoxo, de modo bem diferente, contudo, que percebo a questão das práticas de letramentos que convocam a interpretar. É possível viver a palavra e, ao mesmo tempo, encontrá-la em algum outro lugar que não dentro da própria linguagem em que se vive?

${ }^{6}<$ http://elfikurten.blogspot.com/2011/01/dialogo-com-guimaraes-rosaentrevista.html>. 
Parece-me que esse é o processo no qual também encontramos nosso professor-personagem da discussão, aquele que ouve repetidamente a famosa frase que encerra o livro Watt, de Samuel Beckett: "no symbols where none intended" - não interprete (mas interprete); um imperativo à recusa da interpretação que já carrega consigo o próprio ato de significar outra coisa que ecoa na própria frase e que nos impele a substituir isto por aquilo, em uma "adesão à letra, ao mesmo tempo em que nos provoca de modo bastante explícito a 'ultrapassá-la’” (MARTINS, 2009, p. 3).

Voltando ao Sartre e seu Que é a literatura (mas sem intenção alguma de tratá-lo como uma espécie de panaceia aqui), acredito que certas consideraçôes sobre a leitura (e, portanto, interpretação) apontadas no livro possam ser interessantes quando relacionadas ao que vimos tratando.

Sartre sugere que a leitura (ele também considera da mesma maneira, nesse ponto do livro, a atitude do espectador em relação a uma obra de arte) é uma "síntese da percepção e da criaçãa" (SARTRE, 2004, p. 37); o leitor cria, ao mesmo tempo que desvenda. A leitura é, assim, uma criação dirigida, e a substância do objeto literário (ou obra) é a própria subjetividade do leitor. Isso implica que a realização final da obra literária acontece no ato de leitura, o leitor completa aquilo que o escritor começou. Mas o livro não é um meio para um determinado fim, ele se apresenta como um fim em si mesmo para a liberdade do leitor, inesgotável e opaco, como as coisas:

[...] a obra só existe quando a vemos; ela é primeiramente puro apelo, pura exigência de existir. A obra não é um instrumento cuja existência é manifesta e cujo fim é indeterminado: ela se apresenta como uma tarefa a cumprir, coloca-se de imediato no nível do imperativo categórico. Você é perfeitamente livre para deixar esse livro sobre a mesa. Mas uma vez que o abra, você assume a responsabilidade. Pois a liberdade não se prova na fruição do livre funcionamento subjetivo, mas sim num ato criador solicitado por um imperativo (SARTRE, 2004, p. 41, grifo do autor).

Assim, temos o ato de leitura como um apelo à liberdade do leitorespectador, mas uma liberdade que é devida ao cumprimento do ato em si, e, como Sartre salienta, é também um pacto de generosidade entre autor e leitor, em que confiança e exigência são recíprocas.

Mas como responder às expectativas da prática pedagógica, que insiste em um interpretar que exige o "dizer algo sobre"? 
Parece-me que a ideia de reagir ao texto, em vez de descobrir o que está encoberto, é um caminho mais interessante. Refiro-me a uma proposta de leitura como performance, e uma performance aliada à ideia de Sartre da criação poética: ler-criar. Quando me reporto ao processo do poeta sartreano, não pretendo assimilar em minhas considerações todo o processo do modo como ele nos informa, mas no sentido de observar a linguagem "como se [o poeta] não pertencesse à condição humana"; mesmo reconhecendo que se vive em linguagem, porém com certa atitude de estranhamento em direção a um desacostumar linguístico, ao qual me atrevo a chamar aqui de "atitude poética".

Esse estranhamento possibilitaria observar de dentro, mantendo um distanciamento próximo, um desconhecimento familiar, como para um etnógrafo que precise pesquisar a própria comunidade em que vive. É o que acredito ter possibilitado a Guimarães Rosa escrever sobre algo que lhe era tão próximo, e no qual estava mergulhado, mas de forma diferente daquela a que estava habituado a fazer (o contar oralmente as histórias de seu sertão, e que são as histórias de muitos outros sertões também), em um tipo de "consciência poética", mas que também é instintiva, como ele nos fala em sua entrevista. Algo que é possível por reconhecer o mundo como literatura viva: mundo e literatura que vivem, de modos diferentes, mas paradoxalmente como um mesmo, no cotidiano e nos escritos.

Como Sartre argumenta, "ninguém é escritor por haver decidido dizer certas coisas, mas por haver decidido dizê-las de determinado modo" (SARTRE, 2004, p. 22). Esse investimento é o que distingue o fazer artístico dos letramentos cotidianos, e que, em minha opinião, deve ser observado com atitude poética nas práticas pedagógicas de interpretação: reconhecer no próprio ato de leitura uma necessidade de um ler diferenciado, ler-fazer como o poeta, para criar algo (junto à obra), em um mundo que é, em si, obra também.

Entendo, portanto, que não haja leitura como criaçăo sem leitura do mundo do qual participamos (em diferentes tipos de letramentos), pois viver é também interpretar, é estar sempre sendo letrado em diferentes situações que compõem a vida. Dessa forma, emprestamos à obra aquilo que conhecemos para que nela possa acontecer a vida de outra forma, mas que ao mesmo tempo éa mesma:

a espera de Raskolnikoff é a minha espera, que eu empresto a ele [...] seu ódio contra o juiz que o está interrogando é meu ódio, solicitado, capturado pelos signos, e o próprio juiz não existiria sem o ódio que sinto por ele através de Raskolnikoff; é esse ódio que o anima, é a sua própria carne (SARTRE, 2004, p. 38, grifo do autor). 
Assim, (re)conhecemos e criamos na obra aquilo que vivemos, e assim também podemos vivê-la de modo distinto, emprestando-nos a ela, criando algo que é a obra em si, nós mesmos e a própria vida, de muitas formas, para cada ato de leitura. Por isso enfatizo a necessidade de uma atitude poética, do afastar-se estando dentro: da obra, do mundo, em si mesmo. Um ato de ler como performance, que reage à obra consciente da impossibilidade do sobrevoo, mas imbuído de tal atitude, para poder perceber a força demiúrgica da linguagem, na vã aspiração de contê-la (na obra ou para nós mesmos).

\section{Uma questão de postura}

O exercício de "atitudes poéticas" voltadas às práticas de letramentos que envolvam a interpretação demanda certa postura em relação à linguagem, de forma mais geral. A noção de linguagem como um conjunto de práticas, ou, como na metáfora wittgensteineana, de jogos de linguagem, parece responder às expectativas de um posicionamento que possibilite tal atitude.

No entanto, isso não significa dizer que, ao abraçar essa postura, o desvario dará o tom nas práticas de interpretação. Se não há regras que preexistam ao uso da linguagem, há a noção de regras constitutivas que são aprendidas e usadas quando nos engajamos nas práticas de linguagem, e que tomamos como naturais e necessárias (WITTGENSTEIN, 1999). Essas regras são construídas histórica e culturalmente, portanto não são propriedades naturais ou essenciais do mundo ou de nossa mente, funcionando apenas como critérios que nos permitem julgar algo como adequado em um determinado contexto e situação, de e para determinados falantes. São as vivências, nossas práticas partilhadas em sociedade, que nos permitem estabelecer critérios, que são fixados pelo uso, mas que podem, também, ser revogáveis. Dessa forma, as práticas partilhadas e os critérios possibilitam a estabilização do conhecimento e, portanto, da linguagem para o aprendizado e a comunicação entre as pessoas, afastando a noção de universalismos e essências.

Encarar a linguagem como práxis permite também compreender as relações entre os letramentos escolares e os outros tipos de letramentos que não fazem parte do contexto da escola, isto é, possibilita "atentar para a dinâmica e as múltiplas maneiras de uso social da linguagem, estabelecendo uma ponte entre o que está dentro e o que está fora da sala de aula, de forma a considerar as diferentes vozes e identidades [...]" (SOUZA, 2011, p. 160).

Mas como estabelecer uma agenda de trabalho concreta (e possível) que compreenda a noção da linguagem como um conjunto de práticas e abarque 
essa diversidade de letramentos durante o exercício da interpretação? Que gêneros e textos escolher? Como incentivar, trabalhar e avaliar a interpretação dos textos escolhidos, já que a ideia de um método pronto de ensino para interpretação não tem espaço dentro da noção de práticas? Contudo, paradoxalmente, sabemos que, para as práticas pedagógicas diárias, há a necessidade de alguma organização dos programas de ensino.

Sobre os diferentes gêneros e textos a considerar durante os eventos de letramentos escolares, Rojo (2009) nos traz alguns "princípios norteadores" que julgo pertinentes para nossa agenda de trabalho. A autora chama a atenção para as possibilidades de aprendizagem dos alunos - quais objetos de ensino serão apropriados a uma determinada turma em um determinado momento, isto é, o que é possível para os alunos aprenderem e partilharem em cada etapa do processo. Aliada a essa noção, temos as necessidades de ensino - que gêneros e textos escolher para uma determinada turma, de tal escola, que pertence a tal comunidade de práticas; isto é, aquilo que seja interessante para um grupo em particular, visando a uma formação mais ampla, mas que ao mesmo tempo respeite suas identidades e saberes locais.

Seguindo esses princípios, a escolha dos gêneros e textos será específica para cada turma e etapa de ensino dentro do programa escolar, e nunca uma determinação fixa que promova a homogeneização das diversidades e possibilidades.

Além dos princípios, que possibilitam a seleção, há a questão de como trabalhar os textos em sala de aula. Para essa tarefa, também não acredito em uma metodologia sistemática que garanta uma aprendizagem uniforme e regulada. A noção de práticas permite, contudo, a utilização de uma série de estratégias que incentivam e dinamizam o ato de ler. Dentre a literatura sobre o assunto, BORTONI-RICARDO et al. (2012) trazem resultados de pesquisas que objetivam a construção de uma "pedagogia da leitura", em que o professor atua como um mediador entre o aluno e o texto, utilizando uma série de estratégias de ensino.

Contudo, mesmo as estratégias não podem ser aparatos prontos, anteriores ao próprio uso, ferramentas pré-moldadas com o intuito de criar as mesmas reaçōes nos alunos. Como estratégias voltadas a uma "atitude poética", o professor pode pedir que os alunos tentem fazer relações entre o texto e suas próprias vidas; pode pedir que reajam a certas passagens do texto, dizendo o que acham ou mesmo o que fariam nas mesmas circunstâncias; pode pedir que façam relações com outros textos e gêneros; pode incentivar a percepção 
estética, e perguntar por que eles gostam ou não da forma como o texto foi construído; pode perguntar se construiriam aquele texto da mesma forma ou se fariam diferente, e como fariam; pode discutir as escolhas do autor, a influência da época, da escola literária; pode perguntar como seria ver o mundo através de um determinado personagem e as implicações disso na obra e/ou na vida fora da obra; pode parodiar a obra, realizar uma peça com os alunos sobre a obra, uma adaptação para o cinema, uma pintura, desenho, quadrinhos, canção etc. Enfim, as estratégias são muitas, mas são, como as interpretações que surgem, mais um lance no jogo, e mostram, também, nossa habilidade de jogar, de fazer parte daquelas práticas de linguagem.

Nesse sentido, assim como os alunos, os professores também estão inseridos na linguagem, e não há um lugar fora dela que permita observar o que está acontecendo naquela instância de uso. Ensinar e avaliar são também lances nos jogos de linguagem nos quais os letramentos escolares estão em curso. Logo, abraçar a noção de práxis resulta em um trabalho muito maior para o exercício pedagógico pela possibilidade mais ampla de respostas e reaçóes às práticas de letramentos, assim como para a própria organização dos programas de ensino.

As regras, estratégias, a organização do programa, etc., nessa visão, são definidas durante o jogo, com todos os jogadores dando seus lances. No entanto, isso não significa uma ruptura radical com aquilo que já conhecemos das práticas de ensino que os programas escolares estabelecem. Configura-se justamente como um exercício de reflexão sobre essas práticas e suas normas, regras, limitaçóes, etc., ao se engajar com os alunos no exercício da interpretação. E, em minha opinião, os letramentos como "usos sociais da escrita e leitura”, como práticas, não podem estar dissociados dessa visão, exigindo, pois, uma postura similar no cotidiano da vida escolar.

Por isso defendo esse movimento paradoxal a que chamo "atitude poética" para o ato de ler (em que ler envolve qualquer tipo de ato interpretativo), especialmente durante as práticas de letramentos escolares. Essa atitude, que resulta de uma postura em relação à linguagem perante os letramentos escolares, permitiria ao professor participar com os alunos de um processo que não é estático, que não se restringe às exigências acadêmicas. Sua dinamicidade pode oferecer possibilidades que extravasam os limites da escola, em uma proposta de leitura que é contínua, irredutível e inesgotável, pois que se relaciona com a vida em si, já que é a própria vida. Uma obra-vida que também não exclui o sujeito: não há um texto-além, inalcançável, 
incompreensível, e por mais que um ato de ler crie algo, por mais que a atitude de desacostumar-se/desacostumar a linguagem seja importante, o leitorespectador também se reconhece nele, pois lá ele também está.

Tal atitude poética, que abraça movimentos tão paradoxais, não se configura como um impasse, não é um tipo de embaraço que nos coloca em um lugar sem saída: é ação, reação e criação; mas que não submete nem é submissa, cuja liberdade é tão indizível a ponto de se fazer falar.

\section{Referências}

ARISTÓTELES. Da interpretação. In: Órganon. Bauru: Edipro, 2005. p. 81-110.

BARTHES, R. O prazer do texto. São Paulo: Perspectiva, 2002.

BARTON, D.; HAMILTON, M. Local literacies: reading and writing in one community. London: Routledge, 1998.

BORTONI-RICARDO, S. M. et al. (Org.). Leitura e mediação pedagógica. São Paulo: Parábola Editorial, 2012.

BRASIL. Secretaria de Educação Fundamental. Parâmetros Curriculares Nacionais: Ensino Médio. Brasília: MEC/SEF, 2000.

COPE, B.; KALANTZIS, M. Introduction: multiliteracies: the beginning of an idea. In: (Ed.). Multiliteracies, literacy, learning and the design of social futures. London: Routledge, 2000. p. 3-8.

CULLER, J. Em defesa da superinterpretação. In: ECO, U. Interpretação e superinterpretação. São Paulo: Martins Fontes, 1993. p. 129-146.

DE MAN, P. Impasse da crítica formalista. In: . O ponto de vista da cegueira: ensaios sobre a retórica da crítica contemporânea. Lisboa, Ângelus Novus; Cotovia, 1999. p. 251-268.

ECO, U. Superinterpretando textos. In: . Interpretação e superinterpretação. São Paulo: Martins Fontes, 1993. p. 53-78.

GREEN, L. J. et al. Constructing literacy in classrooms: literate action as social accomplishment. In: RUDDELL, B., RUDDELL, M. R.; SINGER, H. (Ed.). Theoretical models and processes of reading. New York: International Reading Association, 1994. p. 124-154.

KLEIMAN, A. B. Os significados do letramento: uma nova perspectiva sobre a prática social da escrita. Campinas: Mercado das Letras, 1995.

LOCKE, J. Ensaio acerca do entendimento humano. São Paulo: Nova Cultural, 2005. 
MARTINS, H. Beckett e a língua dos outros - que outros? Tradução em Revista, n. 7, p. 1-14, 2009.

OGDEN, C. K.; RICHARDS, I. A. O significado de significado: um estudo da influência de linguagem sobre o pensamento e sobre a Ciência do Simbolismo. Rio de Janeiro: Zahar, 1976.

REDDY, M. J. A metáfora do conduto: um caso de conflito de enquadramento na nossa linguagem sobre a linguagem. Tradução de Hesca Holsbach et al. Cadernos de Tradução, Porto Alegre, n. 9, p. 1-74, jan.-mar. 2000.

ROJO, R. H. R. Letramentos múltiplos, escola e inclusão social. São Paulo: Parábola, 2009.

RORTY, R. A tragetória do pragmatista. In: ECO, U. Interpretação e superinterpretação. São Paulo: Martins Fontes, 1993. p. 105-128.

ROSA, J. G. Entrevista a Pedro Bloch. Revista Manchete, n. 580, jun. 1963.

ROSA, J. G. Diálogo com Guimarães Rosa. Entrevista concedida a Günter Lorenz. 1965. Disponível em: <http://elfikurten.blogspot.com/2011/01/ dialogo-com-guimaraes-rosa-entrevista.html>. Acesso em: 10 nov. 2011.

SARTRE, J. P. Que é a literatura? São Paulo: Ática, 2004.

SOARES, M. Letramento em três gêneros. Belo Horizonte: Autêntica, 1998.

SOARES, M. Alfabetização e letramento: caminhos e descaminhos. Revista Pátio, n. 29, fev. 2004.

SONTAG, S. Contra a interpretação. 1965. Disponível em: <http:// pt.scribd.com/doc/17146409/Contra-a-Interpretacao-Susan-Sontag>. Acesso em: 4 nov. 2011.

SOUZA, A. L. S. Letramentos de reexistência: poesia, grafite, música, dança: hiphop. São Paulo, Parábola, 2011.

STREET, B. V. Literacy in theory and practice. Cambridge: Cambridge University Press, 1984.

STREET, B. V. Cross-cultural approaches to literacy. New York: Cambridge University Press, 1993.

WITTGENSTEIN, L. Investigaçôes filosóficas. São Paulo: Nova Cultural, 1999.

Recebido em 15/03/2012. Aprovado em 18/07/2012. 